\title{
COVID-19 in Nepal: Scarcity of Personal Protective Equipment (PPE) and its Alternative
}

\author{
*Laxmi Panthy ${ }^{1}$, Jagadishwor Panthi ${ }^{2}$ Kapil Amgain ${ }^{3}$, Pooja Thapaliya ${ }^{4}$, Jos Van Laar ${ }^{5}$
}

\author{
Author Info: \\ 1aHaatemalo Abhiyan Nepal \\ (HAN), You Can Save 5 Lives \\ Project Founder \& Director \\ (HAN), Nepal \\ ${ }^{1 b}$ Ministry of Social \\ Development, Gandaki \\ Province, Nepal \\ ${ }^{2}$ Lecturer, Department of \\ Management, West Point \\ College, Myagdi, Nepal \\ ${ }^{3}$ Assistant Professor, Head \\ of Department of Anatomy \\ \& Cell Biology, School of \\ Medicine, Karnali Academy \\ of Health Sciences (KAHS), \\ Jumla, Nepal

\section{${ }^{4}$ MBBS Graduate, USA} \\ ${ }^{5}$ Institute for Preventive \\ Medicine. The University of \\ Maastricht, Health Sciences \\ \& Preventive Medicine, \\ Netherlands
}

\section{*Corresponding Author:}

Dr. Laxmi Panthy; drlaxmipanthy@outlook.com

\begin{abstract}
Background: The Coronavirus Disease (COVID-19), which was first discovered in Wuhan, China in December 2019, puts an entire world under unprecedented danger. Powerful nations such as the United States of America and European Union countries having their hardest time to get sufficient medical protective gear, ensure market operation, and eventually to save people from dying of corona infection. To date, 213 countries have been affected. WHO has confirmed 123,010 deaths and 1914,916 cases with coronavirus positive as of 15 April 2020. It has created a global public health emergency. There is no specific prophylaxis or treatment available yet. Hand washing, covering one's mouth when coughing, social distancing, self-isolation, and quarantine are preventive measures to hamper the spread of disease. Currently, Nepal has entered into the second phase of the outbreak. Health care workers (HCW) at the frontlines of the battle against COVID-19 are ill-equipped to treat coronavirus patients, due to not having adequate personal protective equipment in Nepal. Additionally, there is a shortage of PPE in the world market due to the aggressive buying of PPE globally.
\end{abstract}

Conclusion: In this global scarcity, locally made PPE has become another alternate way for Nepal. Hence, some of the local garments, hospitals, and local rural municipalities have prepared and delivered to HCWs. Although these Nepal-made PPE are not as high quality as imported ones, they at least offer some protection to medical staff. Our recommendations are:

a) Learn- from countries with the lowest mortality rate and best medical \& preventive practices policies, as fast as possible.

b) Alternative: Approaches are necessary to decrease the risk of exposure to HCWs and are safe for patient care in this global market scarcity of PPE.

c) Solidarity- between richer and poorer countries is necessary.

d) Cooperate globally international cooperation between governments, scientists, corporations and health care professionals is not only needed, but also necessary to end this pandemic.

Keywords: Coronavirus, Spread, PPE, Scarcity

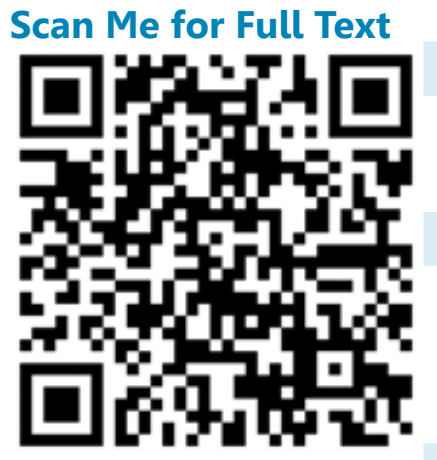
View PDF

Received: 5 April 2020; Accepted: 2 May 2020; Published Online: 4 May 2020

How to cite this article in Vancouver Style? [8/10]

Panthy L, Panthi J, Amgain K, Thapaliya P, Laar JV. COVID-19 in Nepal: Scarcity of Personal Protective Equipment (PPE) and its Alternative. Europasian J Med Sci.2020;2(1):74-80. https://doi.org/10.46405/ejms.v2i1.47

Conflict of Interest: None Declared;

\section{Disclaimer}

Copyright: (c) 2020 by author(s). This is an open access article distributed under the terms of the Creative Commons Attribution International License 4.0. Which permits unrestricted use, distribution, and reproduction in any medium, provided the original work is properly cited.

\section{Publisher's Note}

The Europasian Journal of Medical Sciences (EJMS) remains neutral with regard to jurisdictional claims in published articles and institutional affiliations. 


\section{BACKGROUND}

Coronavirus disease 2019 (COVID-19) is a respiratory tract infection caused by a newly emergent coronavirus (severe acute respiratory syndrome coronavirus 2; SARS-CoV-2) ${ }^{1}$. The outbreak was first noted in Wuhan, Hubei province, China, in December 2019. In January 2020, the flare-up of the 2019 novel coronavirus (2019-nCoV) in China spread continuously to other nations ${ }^{2}$, with the $\mathrm{WHO}$ declaring it a Public Health Emergency of International Concern ${ }^{3}$ on January 30,2020 , and recognized it as a pandemic on March 11, 2020, ${ }^{3}$. The title coronavirus comes from the Latin word crown or halo, meaning corona. Coronaviruses are a member of the large family of viruses that cause mild sickness like the common cold to extreme illnesses such as the Middle East respiratory syndrome (MERS) and severe acute respiratory syndrome (SARS). ${ }^{16}$

SARS killed $10 \%$ of infected people whereas MERS was lethal in $37 \%$ of the contaminated population. The current global fatality rate of Coronavirus is $2.2 \%$. If we describe this statistically in reverse, almost $98 \%$ of virus-infected do not die. ${ }^{17}$ The coronavirus is influencing 213 nations and territories around the world ${ }^{4}$. Among the affected countries beyond China (coronavirus positive cases 1914,916 and 123,010 deaths were reported as of April 15, 2020) are others in Asia, Europe, and the
USA including Nepal. Moreover; 494,578 people have recovered. 4,15 The countries with the most cases are USA $(578,268)$, Spain (172.541), Italy $(162,488)$, Germany $(102,533)$, France $(93,877)$, UK $(93,877)$, China $(83,745)$, Iran $(74,877)$ and Turkey $(65,111) .{ }^{15}$ In Europe and USA, as we saw until now, the case-fatality rates, in general, can be very high (between $1 \%$ and $10 \%$ dependent on the country, in most countries the case-mortality rate is higher than 5\%), but we need more testing \& precise research to know the exact numbers. ${ }^{23}$ (Fig.1).

Nepal has entered into the second phase of the outbreak. Hospital staffs in Nepal at the Frontlines of the battle against COVID-19 are ill-equipped to treat coronavirus patients, as they don't have an adequate number of personal protective equipment. ${ }^{11}$ As the COVID-19 pandemic sweeps the globe, hospitals have been overwhelmed. For the past month, hospitals across Nepal have been treating patients' coronavirus symptoms without proper PPE, and the medical system is ill-prepared for a major outbreak. Since a few units of PPE are not going to be enough, and because they are so expensive, therefore; there is no choice but to start making them locally is the best alternate way.

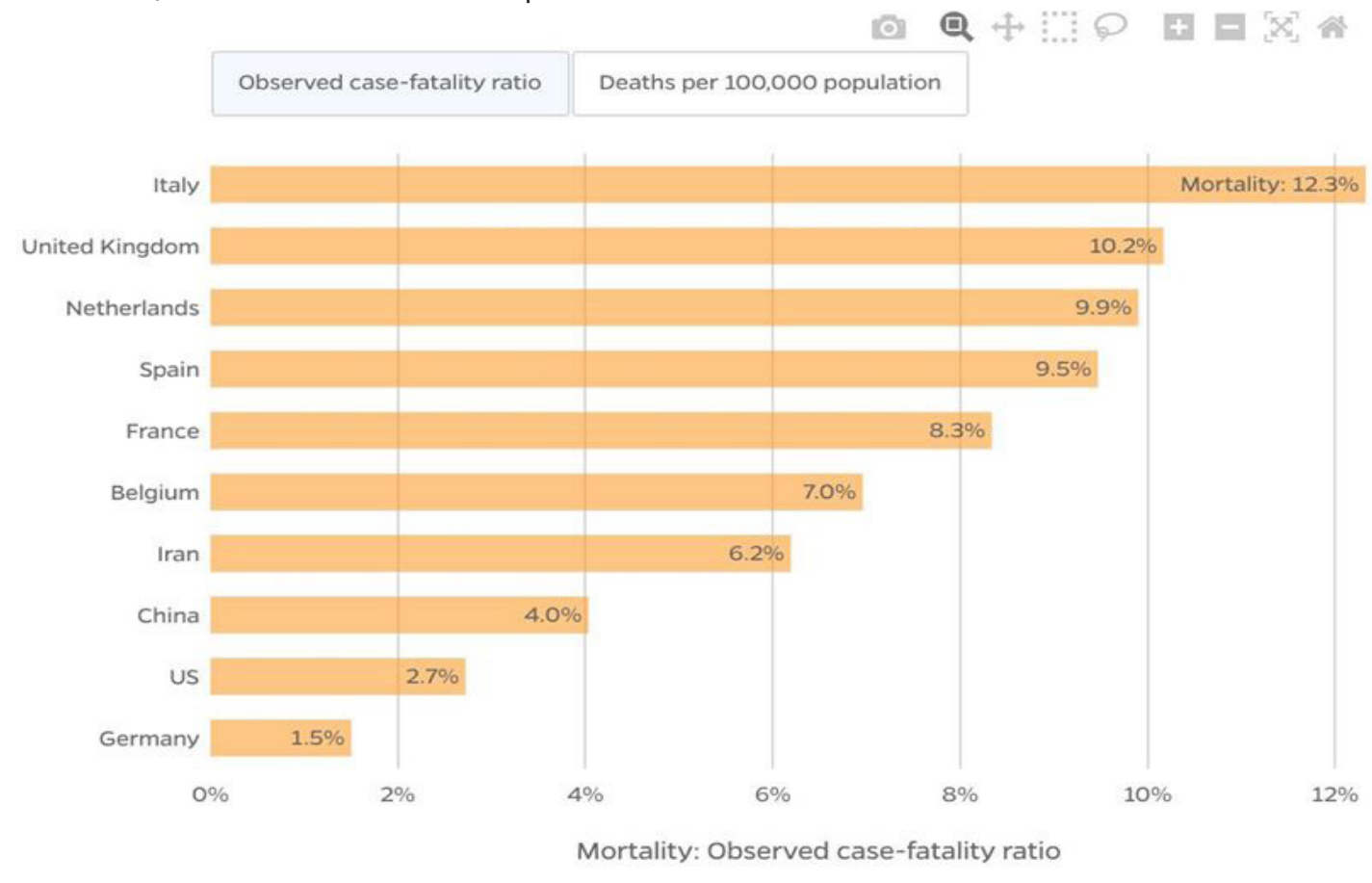

Figure 1: Global burden of Mortality and observed case-fatality ratio 


\section{HOW TO SPREAD AND OUR CONCERN}

Although the average fatality rate of COVID-19 is $2.2 \%{ }^{17}$; the question arises here is, why is there so much concern to COVID -19 outbreak, given the relatively low mortality rate in comparison to previous coronavirus episodes?

Firstly, the coronavirus discovered in Wuhan is 'novel'. This word is used in viral epidemiology to indicate a new strain, one which has not been identified previously in the population. Researchers, therefore; do not have satisfactory data regarding the characteristics of the infection to provide evidence-based public health instructions on control and treatment.

Secondly, unlike SARS and MERS, this virus has an incubation period of up to 14 days and asymptomatic infected individuals can transmit the disease to others in that period. Even infected persons who show improvement can continue to transmit the infection. ${ }^{17}$ The RO value of COVID 19 is estimated at 3 , meaning that who gets the disease on average will transmit to three other people. This is often considered as high infectivity, but still lower than that of SARS or MERS. ${ }^{18}$ (Fig2)

COVID-19 is spread during close contact and by small droplets produced when infected person coughs, sneeze or conversation. These small droplets may also be produced during breathing; however, they rapidly fall to the surfaces and are not generally spread through the air over large distances. People mav also become infected bv

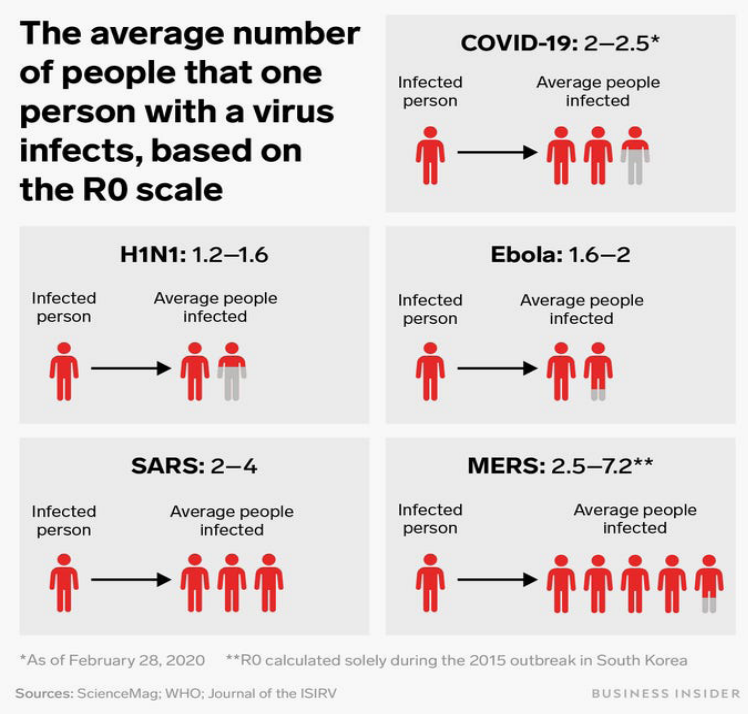

Figure 2: Global Burden of Different types of Virus touching a contaminated surface and then their own face. The virus can survive on surfaces for up to 3 day ${ }^{5}$.It is most contagious during the first three days after onset of symptoms, although spread may be possible before symptoms appear and in later stages of the disease. An incubation period of this virus typically around five days, but may extend from 2-14 days ${ }^{12}$.

Most Common symptoms include fever, cough, and shortness of breath. Complications may include pneumonia and acute respiratory distress syndrome. ${ }^{3}$ There is no specific prophylaxis or treatment available yet for COVID 19: Primary treatment is symptomatic ${ }^{14}$. The best way is to prevent it by keeping the WHO guidelines: Make sure we don't get it and we do not spread it: wash hands, keep a safe distance, stay inside as much as possible and do much more testing, so we can isolate those, who have COVID, so we can interrupt and hopefully soon, when we have a working vaccine, stop the infection cycle 16,22

\section{INFECTION PREVENTION AND CONTROL (IPC) MEASURES}

A. Initiate IPC - at the point of entry of the patient to the hospital. Screening should be done at the first point of contact at the emergency department, /outpatient department /fever clinics. Suspected patients should be given a mask and directed to a separate area. Keep at least $1 \mathrm{~m}$ distance between suspected patients. ${ }^{6}$

B. Standard precautions - Standard precautions include hand washing and the use of PPE when in contact with patients' body fluids, secretions (including respiratory secretions) and nonintact skin. Standard precautions also include prevention of needle or sharp injuries; safe waste disposal; disinfection of equipment; and cleaning of the environment. ${ }^{6}$

C. Point-of-care risk assessment - should be done at every patient contact to ensure whether extra safety measures are required

\section{PPE SCARCITY}

Recent studies showed that COVID-19 transmitted rapidly. Personal protective equipment (PPE) is used every day by healthcare personnel (HCP) to protect themselves, patients, and others when providing care. ${ }^{7}$ PPE includes gloves, long-sleeved gowns, eye protection/glass or goggles, and fittested particulate respirators (N95 or equivalent, or higher level of protection). PPE helps to protect HCP from potentially infectious patients and materials, 
toxic medications, and other potentially dangerous substances used in healthcare delivery ${ }^{6,7}$.

Recently, PPE shortages are posing a huge challenge to the healthcare framework around the world because of the COVID-19 pandemic. Healthcare offices are facing trouble getting to the required PPE and are having difficulty identifying alternate ways to provide patient care ${ }^{7,8}$. Nepal is ahead of the curve, but if the corona caseload is to rise steeply as it has done in Italy or Spain, The Nepal government needs to arrange alternatives ${ }^{8}$. Nepal has entered into the second phase of the outbreak, with the confirmation of the first locally transmitted COVID-19 case in Nepal, epidemiologists have cautioned that the case could be a sign of a possible outbreak of the dangerous illness within the nation ${ }^{9}$. Nepal has a total of thirty active cases of COVID-19, while two patients have already recovered from the virus (17 April 2020) 10,19. At present, nurses, doctors, interns and resident doctors and other medical personnel in Nepal's hospitals lack personal protective equipment (PPE), and they fear for their own lives while treating patients with suspected coronavirus ${ }^{8}$. Patients can be carriers and spreaders of the virus without showing any symptoms. Thousands have been visiting hospitals to get tested, have chest $\mathrm{x}$-rays done, and could be unknowingly infecting medical staffs and other patients. Healthcare workers in Nepal are stressed because PPE supplies are limited, runnina low, or

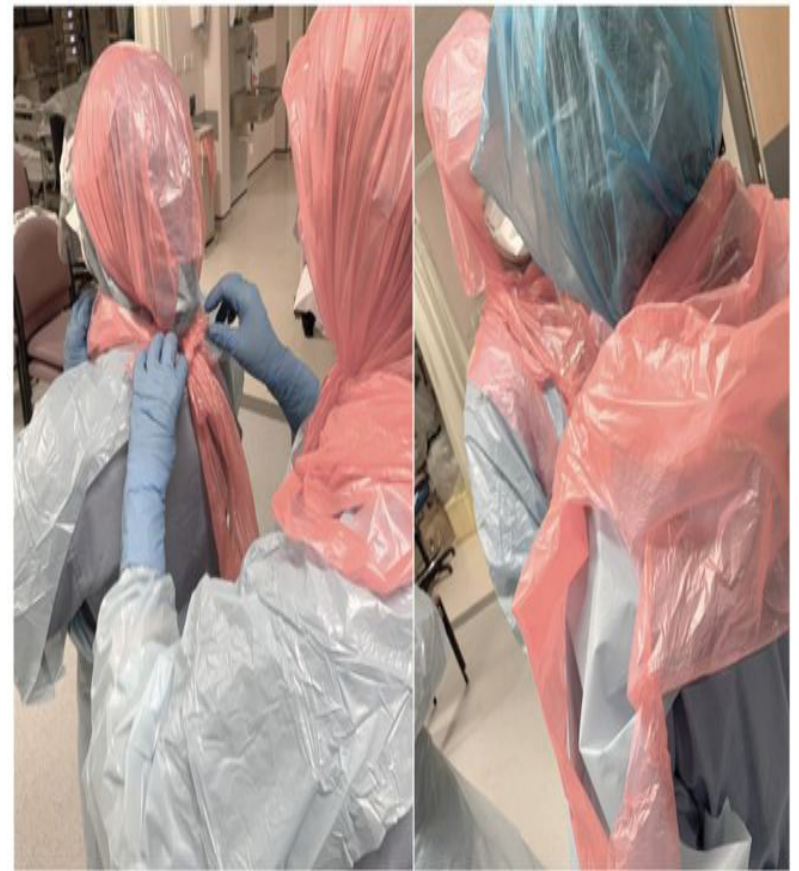

Figure 3: The NHS workers wearing bin bags as protection (BBC News, April 5, 2020)
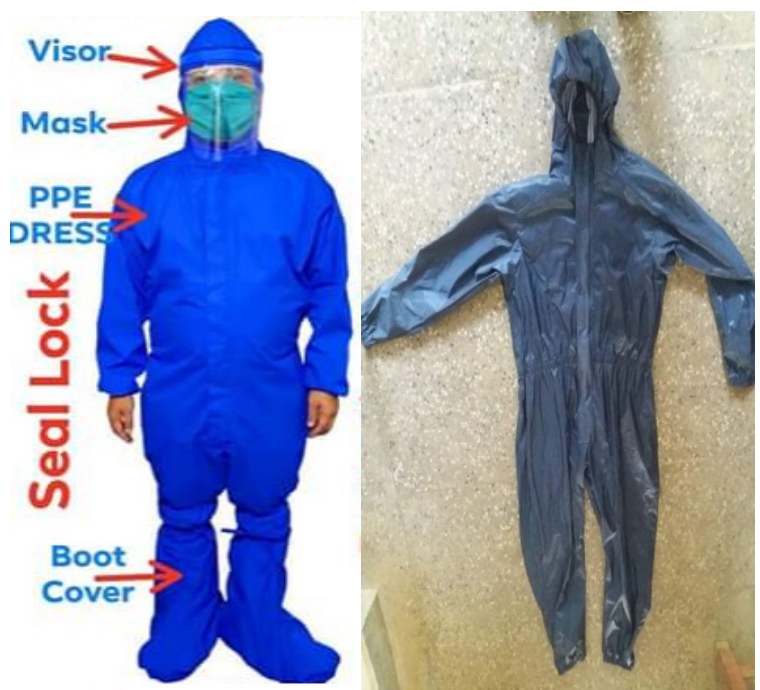

Figure 4: PPE Gown/Aprons

absent in many hospitals. Moreover; Nepal doesn't have own factories to produce standard PPE, needs to import from abroad. And there is a shortage of PPE in the world market. Donor countries can't respond because they are dealing with shortages themselves ${ }^{11}$. Several healthcare workers (HCWs) in England have told the BBC news of a lack of equipment in their hospitals. HCWs are designing PPE from clinical waste bags, plastic aprons and borrowed skiing goggles ${ }^{20}$.

\section{AVAILABILITY \& SUPPLY OF PPE GLOBALLY}

In 2019, the worldwide market value for PPE (covering all major industry segments, including manufacturing, oil and gas, as well as healthcare) was valued at an estimated US\$ 50.9 billion. Though, with the impact of the COVID-19 outbreak, demand for some PPE products specifically used in response to COVID-19 has increased as high as 1000-2000 fold than of annual demand. For example, the normal annual requirement of both gowns and coveralls by UNICEF on behalf of some low- and middle-income countries for 2017-2019 did not exceed 50,000 units per year. Recently, UNICEF's demand estimates for gowns and coveralls for three months is approximately 25 million units. Similarly, the annual average usage for all different types of face masks sourced via UNICEF did not exceed 25,000 units. In contrast, the current need for face masks, both surgical and N95 masks, in response to COVID-19 surpasses 55 million. Additionally, China is the largest producer of PPE products, produces $50 \%$ of global masks, as well as of many of the raw materials needed to manufacture these products. Forty-six nations have so far submitted forecasts for PPE supplies ${ }^{21}$. Despite the market scarcity due to 

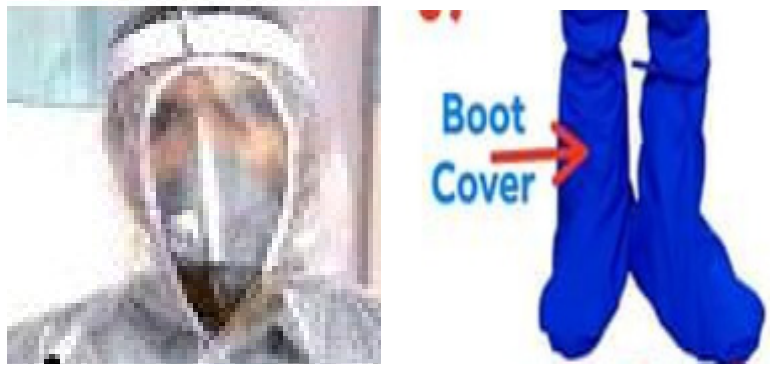

Fig.5: Goggles \& Helmet Fig. 6: Boots/

\section{footwear}
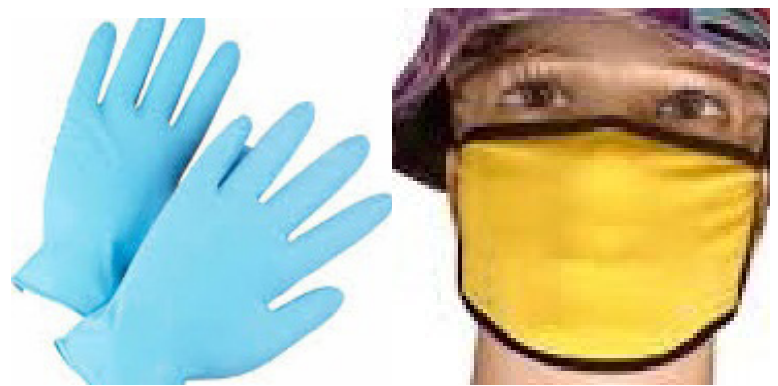

Figure 7: Gloves

Figure 8: Face Mask

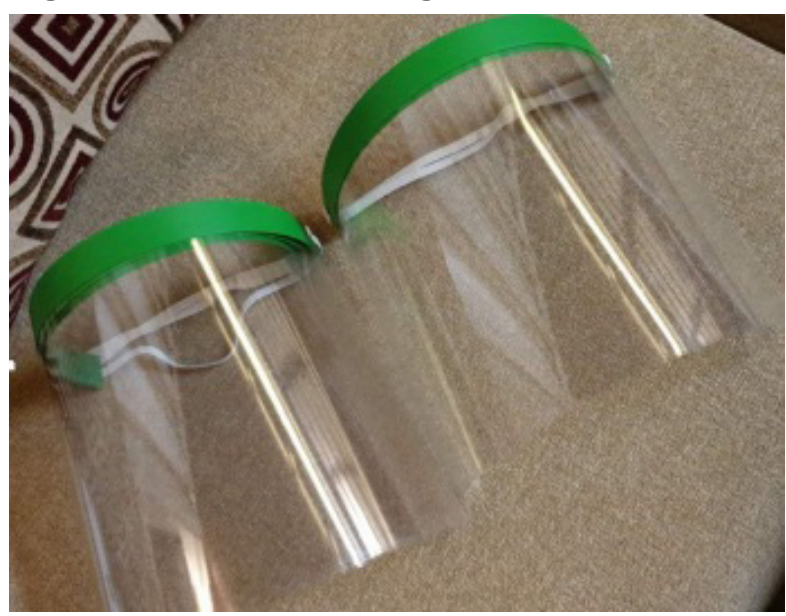

Figure 9: Face Shied

aggressive buying, since the end of January, UNICEF has effectively secured 7.4 million surgical masks, 4 million respirators, 2.2 million surgical gowns, 1.8 million coveralls, aprons and 11,600 infrared thermometers, among numerous items, a portion of which has already been delivered to countries. And UNICEF is engaged with 1000 suppliers to find a solution to current market demand. ${ }^{21}$

\section{STRATEGY \& ALTERNATIVE PPE IN NEPAL}

There are several ways to minimize PPE uses. Such as:

1. Altering work practices to minimize patient contacts.

2. By canceling non-urgent and elective procedures/appointments.

3. Encourage to prepare re-usable PPE and reuse it as it can be reprocessed.

4. Consider permitting HCPs to increase the use of respirators, facemasks, and eye protection, more than a single patient contact.

5. Carefully prioritize PPE use of selected procedures. This could include reserving sterile gowns and gloves for urgent sterile patient procedures, such as surgery, and reserving respirators for aerosol-generating procedures and patient care with airborne transmitted disease risks, like tuberculosis, measles, and varicella.

6. Use appropriate PPE for specimen collection (droplet and contact precautions for URT specimens; airborne precautions for LRT specimens). When collecting URT samples, use viral swabs (sterile Dacron or rayon, not cotton) and viral transport media.

7. If commercial PPE is not available, carefully consider if alternative approaches will decrease the risk of HCP exposure and are safe for patient care.

\section{PPE ALTERNATIVE APPROACHES IN NEPAL}

At Present protective gear is being manufactured at different sites in the country, such as the Innovation Centre of Mahabir Pun, the Karnali Academy of Health Science, Bheri Hospital, the Dharan-based BP Koirala Health Science Institute, Nick Simon Institute, Sambridhi Garment Nawalpur, Dhaulagiri Zonal Hospital, etc. Recently local municipalities are taking active steps to prepare PPE items locally and distributing within their own municipalities health offices, drivers, community health workers. Moreover, some social organizations, businesspersons are donating little equipment to health institutions. Although these Nepal-made PPE are not as high quality as imported ones, they at least offer some protection to medical staff. One imported PPE can cost anywhere up to Rs 20,000 , but a locally manufactured one costs from Rs 500-2500. The PPE also needs to be disposed of properly after use in the medical wards, the ICU or even in front of a patient getting tested for COVID-19. One doctor or nurse needs at least eight units of PPE every day. Locally made PPEs are cheap but effective and serve the purpose for now. Some locally prepared PPE alternatives are 
illustrated below ${ }^{10,11}$

Head to toe gowns, aprons have been prepared from locally available materials; thin plastic, waterproof and airproof, fabric clothes (fig. 4). Goggles have been made from transparent stationery, while the helmet is fashioned out of elastic apparel material (fig. 5) and Rubber gloves \& Plastic gloves have been used (fig. 7). A face shield is intended to protect the wearer's face and the eyes from hazards, droplets, etc. At the present health care workers $(\mathrm{HCW})$, Police, Ambulance Driver and municipalities are using it which is made from stationery items such as clear binding sheets, elastic bands, rubber foams, etc. (fig. 8).

Similarly, Boots are made of robust, waterproof material. This also increases the protection from sharp objects like needles and syringes. They are made from a chemical-resistant material. It will be reused. Foot-covers have been made from waterproof and airproof, fabric clothes at least that covers up to calf height. Some coveralls have integrated foot parts (fig. 6). The Mask is prepared from cotton clothes with a double layer. Surgical masks also have been used. (fig. 8) Hand Sanitizer Alcohol mixed with aloe Vera solution is being used.

\section{SOLIDARITY \& LESSONS TO LEARN}

Maybe the biggest lesson from this COVID infection is, that we are all connected globally because the virus knows no borders, all continents are now infected and that it is not wise to kill and eat wild animals like bats and many others because many more diseases came in the past from that very dangerous behavior and will come in near future if we don't change.

The biggest worry, besides the huge explosion in the USA and richer countries, is now the poorer countries, regions and people in Africa, South America and Asia, who will not be able to get the medical care, medicines and preventive materials they need and also the economic crisis caused by this lockdown will hit them even harder than the richer countries, so we hope that the richer countries will not have a blind eye for these poorer countries and help them, with modern effective health care and economic support.

The hope from us all is that we soon find a vaccine and or medicine to be shared between all countries, also with these poor regions and people, by excellent global cooperation and solidarity between scientists, health professionals, health corporations government and international health and humanitarian organizations..$^{23,24}$

It would be good, to create an international task force, to look after these goals and make sure, that also the poorer countries in Africa, Asia and South America get the help they need, as Dr. Sybesma, the COVID coordinator from the Netherlands advised in a TV talk show about this immense COVID and economic crisis, (Buitenhof, 12-4-2020) and the warning was given by Dr. Sybesma, that many people could die in very near future from the economic and poverty problems following the rising COVID related health \& social problems, especially in these poorer areas. ${ }^{25}$

\section{RECOMMENDATIONS}

1 Learn from countries with the lowest mortality rate and best medical \& preventive practices policies, as fast as possible.

2 Cooperate globally across borders, to develop a vaccine, better therapies \& medicines, improve patient care \& preventive policies, so we all benefit. Right now we cannot control and stop it, so more international cooperation between governments, scientists, corporations and health care professionals is not only needed, but necessary to end this pandemic.

3. Solidarity between richer and poorer countries is necessary (also see points above, in SOLIDARITY \& LESSONS TO LEARN )

4. Alternate Approaches - alternative approaches (as shown in table no. 1 above) will decrease the risk of HCW's exposure and are safe for patient care in this global market scarcity.

\section{SUMMARY}

Infectious diseases of high consequence are serious threats to human health. Patients develop severe symptoms, require a high level of care, and the case-fatality rates can be high. Often, there is no specific prophylaxis or treatment available. COVID is transmissible from human to human (contagious) and therefore requires transmission precautions in HCWs. Staff protection with PPE and isolation, quarantine of contagious patients are the main principles to halt the infection. In light of the current Corona outbreak, to keep the balance between safety measures recommendations and the demands of an ongoing emergency along with scarcity in the world market, locally prepared PPE alternatives seem to be useful fighting against 
the COVID-19 outbreak in Nepal until quality PPE arrived. ${ }^{26}$ We need to develop effective therapies, medicines and vaccines together, share protective materials \& increase production. We need to learn from those countries, who have the lowest mortality rate. We need more and more cooperation, globally.

\section{REFERENCES}

1. World Health Organization. Clinical management of severe acute respiratory infection (SARI) when COVID-19 disease is suspected. Interim guidance. March 13, 2020 [Link]

2. Huang $C$, Wang $Y$, Li X, Ren L, Zhao J, Hu Y, Zhang L, Fan G, Xu J, Gu X, Cheng Z. Clinical features of patients infected with 2019 novel coronavirus in Wuhan, China. The lancet. 2020 Feb 15;395(10223):497-506. https://doi.org/10.1016/S0140-6736(20)30183-5 Google Scholar I Crossref

3. WHO. Statement on the second meeting of the International Health Regulations (2005) Emergency Committee regarding the outbreak of novel coronavirus (2019-nCoV). [Link]

4. Worldmeters. Coronavirus News Updates. Confirmed Cases and Deaths by Country, Territory, or Conveyance, April,15, 2020 [Link]

5. "New coronavirus stable for hours on surfaces". National Institutes of Health (NIH). March 17, 2020. [Link\}

6. WHO. Clinical management of severe acute respiratory infection (SARI) when COVID-19 disease is suspected. Interim Guidance. March 13, 2020. [Link]

7. CDC. Coronavirus Disease 2019(COVID-19) Strategies to Optimize the Supply of PPE and Equipment. [Link]

8. NepaliTimes. Protecting those who protect us from the epidemic [Link]

9. Ministry of Health Nepal COVID-19, Response Web Portal. Corona Updates. April 5, 2020

10. MyReppublica. Nepal in second stage of COVID-19 transmission Published On: April 5, 2020. [Link]

11. Himalayan News Service. Protective gear shortage imperils health workers Published: March 26,2020 [Link]

12. "Symptoms of Novel Coronavirus (2019-nCoV)". US Centers for Disease Control and Prevention. February 10, 2020. Retrieved February 11, 2020.

13. Velavan TP, Meyer CG. The COVID-19 epidemic". Tropical Medicine \& International Health. 2020: 278-80. https://doi.org/10.1111/tmi.13383 Crossref
14. Q\&A on coronaviruses. World Health Organization. February 11, 2020. Retrieved 24 February 2020. [Link]

15. World Health Organization. COVID-19 Dashboard, April 15, 2020 [Link]

16. Amgain K, Neupane S, Panthi L, Thapaliya P. Myths versus Truths regarding the Novel Coronavirus Disease (COVID-2019) Outbreak. Journal of Karnali Academy of Health Sciences. 2020;3(1). 1-4. https:// doi.org/10.3126/jkahs.v3i1.28367 [Google Scholar I Full Text

17. Nepali Times. Why Nepal must watch Coronavirus, but not panic? Jan 29, 2020 [Link]

18. Business Insider. An average coronavirus patient infects at least 2 others. To end the pandemic, that crucial metric needs to drop below 1 - here how get there. April 16, 2020. [Link]

19. people test positive for COVID-19 in Nepal, total cases reach 30. April 17, 2020 [Link]

20. BBC News. Coronavirus: The NHS workers wearing bin bags as protection. April 5, 2020 [Link\}

21. The UNICEF. COVID-19 impact assessment and outlook on personal protective equipment. March 25, 2020. [Link]

22. Sajed AN, Amgain K. Corona Virus Disease (COVID-19) Outbreak and the Strategy for Prevention. Europasian Journal of Medical Sciences. 2020 Mar 29;2(1):1-4.https://doi.org/10.46405/ejms. v2i1.38 [Google Scholar | Full Text

23. Asmita Priyadarshini Khatiwada and Sunil Shrestha, Pharmacy Patronage: Identifying the Roles of Nepalese Pharmacists in Tacking COVID-19, J. Pure Appl. Microbiol., May 2020; 14(Spl Edn.). https://doi. org/10.22207/JPAM.14.SPL1.31 Full Text

24. Shrestha R, Shrestha S, Khanal P, Bhuvan KC. Nepal's First Case of COVID-19 and public health response. J Travel Med. 2020;24. https://doi.org/10.1093/jtm/ taaa024 Google Scholar | PubMed | Crossref | Full Text

25. John Hopkins Corona Virus Resource Center https:// coronavirus.jhu.edu/map.htm [Link]

26. Marahatta S, Paudel S, Aryal N. COVID-19 Pandemic: What can Nepal do to Curb the Potential Public Health Disaster?. JKAHS. 2020; 3(1):1-4. https://doi. org/10.3126/jkahs.v3i1.28374 Link 